\title{
Motivation in sport and exercise: a comparison between the BRSQ and BREQ
}

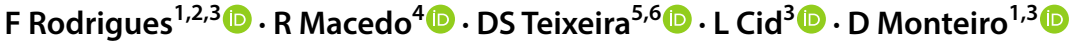 \\ Published online: 18 April 2020 \\ (c) Springer Nature B.V. 2020
}

\begin{abstract}
This study aimed to test whether the Behavioral Regulation in Sport Questionnaire and the Behavioral Regulation in Exercise Questionnaire can measure the same constructs in an equivalent manner. Advanced statistical procedures were used to examine if these scales could be interchangeably applied to the sport and the exercise context. In total, 2256 individuals (athletes $=1099$; exercisers $=1157$ ) completed translated and validated questionnaires measuring all types of motivation based on Self-Determination Theory. Several measurement models were tested, such as confirmatory factor models, exploratory structural equation models, and bifactor specifications. The exploratory structural equation modelling approach provided the best fit to the data in both groups. Multigroup analysis was performed within samples and between athletes and exercisers. Measurement model invariance was confirmed between samples from the same context; however, it did not achieve equivalence between scales. We hope this examination of context invariance analysis using specific validated scales can further help advance conceptual understanding of the measurement in sport and exercise.
\end{abstract}

Keywords Physical activity $\cdot$ Sport $\cdot$ Exercise $\cdot$ Self-determined motivation

F Rodrigues

frodrigues@esdrm.ipsantarem.pt

1 Sport Science School of Rio Maior (ESDRM-IPSantarém), Av. Dr. Mário Soares nº110, 2040-413 Rio Maior, Portugal

2 Life Quality Research Center (CIEQV), Santarém, Portugal

3 Research Center in Sport, Health and Human Development (CIDESD), Vila Real, Portugal

4 Center for Organizational and Social Studies of P. PORTO, (CEOS.PP P. PORTO), Porto, Portugal

5 Lusófona University of Humanities and Technology (ULHT), Lisbon, Portugal

6 Interdisciplinary Center for the Study of Human Performance (CIPER), Lisbon, Portugal 


\section{Introduction}

\subsection{Conceptual framework}

Since the 1980's, Self-Determination Theory (SDT; Deci and Ryan 1985) has shown to be the most relevant theoretical approach towards the study of motivation (Ryan et al. 2019). This theory examines the connection between individual personality and the context in which it is inserted. Thus, SDT seeks to explain motivation in different domains such as health (Hagger and Chatzisarantis 2009), work (Deci et al. 2017), and physical activity (Teixeira et al. 2012; Rodrigues et al. 2018).

Understanding the type of motivation an individual experiences during physical activity consists of great asset to forecast possible outcomes (Hagger et al. 2014). Thus, some measures of motivation may help distinguish between these different dimensions of motivation, whereas others may present bias results. In exploring the measurement of motivation, this study will examine in detail two validated scales, which have been used in the physical activity domain, specifically in sports and exercise context. This study intends to examine the effect of context on the assessment of motivation. Results will contribute to the literature on understand how researchers and professionals should use context validated scales when analyzing individual behavioral regulation towards physical activity.

\subsection{The motivational continuum}

Contrary to past research distinguishing motivation as a dichotomous extrinsic and intrinsic response, SDT postulates motivation based on the degree of perceived self-determined behavior. Specifically, Deci and Ryan (1985) proposed several types of behavioral regulation along a motivational continuum. At one end of the self-determination continuum stands amotivation, defined as the absence of any type of motivation or lack of intention to act upon. That is, the individual does not know why to engage in the behavior or does not seek to continue doing it in the future (Ryan and Deci 2017). At the other end of the motivational continuum stands intrinsic motivation. This type of behavioral regulation is the most self-determined form of motivation, considering that the individual acts on the behavior at his own will, that is, based on the experience of pleasure and enjoyment inherent to the behavior (Deci and Ryan 1985). In between the two poles of the continuum (i.e., amotivation and intrinsic motivation) are four types of extrinsic motivation, varying on the degree of self-determined behavior.

External regulation, close to amotivation, explains how the behavior is initiated and maintained solely for the sake of external rewards or to satisfy others' needs. Still with external locus of causality but with a small degree of internalization arises introjected regulation, defined as acting on the behavior to avoid feelings of guilt related to internal pressures (Deci and Ryan 2008). Identified regulation presents a higher degree of internalization, the individual acts on the behavior because of the benefits innate to its performance. Lastly, the most proximal behavioral regulation to intrinsic motivation is integrated regulation, defined as the form of motivation that arises when an individual has fully integrated the behavior within himself (Ryan and Deci 2017).

Empirical studies in the sport and exercise context have shown that individuals with autonomous or more self-determined motivational patterns (i.e., identified and integrated regulation, and intrinsic motivation) tend to have more favorable attitudes towards the 
behavior, such as higher levels of enjoyment (Gardner et al. 2017; Teixeira et al. 2019), persistence (Rodrigues et al. 2019), and satisfaction with life (Moreno-Murcia et al. 2017). Contrarily, individuals with controlled or less self-determined motivational profiles (introjected and external regulation, and amotivation) directed towards sport or exercise practice are more favorable to maladaptive processes increasing the chances of drop-out (Teixeira et al. 2012), burnout (Bartholomew et al. 2011), or depressive symptoms (Ng et al. 2013).

\subsection{Measures of motivation}

Valid and reliable measures are precursors to the understanding of motivation (Clancy et al. 2017). Hence, over the past decades, a considerable number of instruments based on SDT were developed to help researchers and professionals examine overall changes in behavioral regulations on contextual levels.

The Behavioral Regulation in Exercise Questionnaire (BREQ; Mullan et al. 1997) later reviewed by inserting the measure of amotivation (BREQ-2; Markland and Tobin 2004) and integrated regulation (BREQ-3; Wilson et al. 2007) has been extensively used in the exercise context (Teixeira et al. 2012). This could be related to the fact that the BREQ-3 is the only known instrument to measure all types of motivation based on the SDT framework for the exercise context. This 24-items instrument (four items for each factor) has achieved construct validity and internal consistency in several empirical studies (Cid et al. 2018; Rodrigues et al. 2019; Wilson et al. 2007).

There are several measures in the sport context concerning the measurement of motivation based on SDT. The Sport Motivation Scale (SMS; Pelletier et al. 1995) later shortened to a 24-item version and infusing the integrated regulation subscale (SMS-6; Mallett et al. 2007), and its latter revision (SMS-II; Pelletier et al. 2013), and the Behavioral Regulation in Sport Questionnaire (BRSQ; Lonsdale et al. 2008) have been identified as the most cited instruments in the sport domain (Clancy et al. 2017). Despite extensive literature supporting the use of the SMS-II and BRSQ, Lonsdale et al. (2014) have found both scales to show relative strengths and weaknesses. All in all, the BRSQ has shown to be better suited for competitive or professional athletes, presenting itself as a reliable measure of motivation, while the SMS-II is a more adaptive scale, suitable for other physical activity related contexts (Clancy et al. 2017).

\subsection{Limitations of past research}

When it comes to the measurement of SDT motivational constructs such as behavioral regulations, Ntoumanis and Biddle (1999) have stated that research should be performed within specific cultures and contexts. Hence, scales validated in one context should not be used in another prior to its validation. One of the SDT founder (Ryan 1995) explains the need to use validated scales to measure constructs inherent in the SDT framework. Important methodological limitations associated with non-adaptation and validation of questionnaires may compromise results displayed in several studies (Chen 2008). It seems wise to use the BRSQ only in sports settings, as it seems unsuitable for measuring motivation in the exercise or physical activity domain (Clancy et al. 2017). The same principle applies to the measurement of motivation based on the BREQ-3.

Although it may be reasonable to follow the principle of using context validated scales, several studies have used the BRSQ and the BREQ-3 in other contexts without proper adaptation and validation. For example, studies have applied the BREQ-3 in individuals with 
schizophrenia (Costa et al. 2018), presenting several shortcomings such as several crossloadings and lack of internal consistency on several factors (i.e., amotivation, identified, and introjected regulation). Other studies do not report internal consistency scores at all (Puigarnau 2017) and past research has measured behavioral regulation using the BREQ-3 without item adaptation to the sports context (Román et al. 2019; Tornero-Quiñones et al. 2019). More alarming is the use of the BRSQ or BREQ-3 without translation and validation to the culture under analysis. Specifically, some Portuguese studies have used the BREQ-3 in the sports context (Román et al. 2019) or applied this scale to sedentary individuals (Costa et al. 2018) without adequate construct validity analysis, which could bias reported results (Chen 2007). Finally, there are clear distinctions between the BRSQ and BREQ-3 questionnaires (e.g., item meaning, context) that make them applicable to certain research questions and not others.

\subsection{Current research}

This study aimed to test whether the BRSQ and BREQ-3 can measure the same constructs in an equivalent manner. We used advanced statistical procedures to examine if these scales measure consistently all behavioral regulations based on the SDT framework. Specifically, several Confirmatory Factor Analysis (CFA), Exploratory Structural Equation Modelling (ESEM), and bifactor specifications will be performed to examine the psychometric proprieties of each scale, and to analyze if the constructs are equivalent among groups. Regarding past SDT literature, it is hypothesized that even though the BRSQ and BREQ-3 measure the same constructs underlying the SDT framework (Ryan and Deci 2017), the measurement model will not achieve equivalence between contexts (Chen 2008) due to the differences at the contextual level.

\section{Methods}

\subsection{Participants}

Athletes were 1099 Portuguese adults from three samples $\left(\mathrm{n}_{\mathrm{a} 1=}=301 ; \mathrm{n}_{\mathrm{a} 2}=344 ; \mathrm{n}_{\mathrm{a} 3}=454\right)$ engaged in eight soccer or swimming clubs $\left(M_{\mathrm{age}}=29.12 \pm 4.09\right.$, range $=18$ to 44 ; female $=53.12 \%)$. On average, participants had 57.42 months $(S D=4.75)$ of sport experience and trained 5.11 times $(S D=1.74)$ per week.

Exercisers comprised 1157 Portuguese adults from three samples $\left(\mathrm{n}_{\mathrm{e} 1}=351 ; \mathrm{n}_{\mathrm{e} 2}=401\right.$; $\left.\mathrm{n}_{\mathrm{e} 3}=405\right)$ from several gym and health clubs $\left(M_{\mathrm{age}}=32.35 \pm 3.24\right.$, range $=20$ to 56 ; female $=53.12 \%)$. On average, participants had 45.14 months $(S D=7.43)$ of exercise experience and exercised 2.02 times $(S D=.48)$ per week.

\subsection{Procedures}

Current study was approved by the ethical committee and research was conducted according to the Helsinki declaration and its latter amendments. Then, gym and health club managers as well as team and sport coaches were contacted and objectives were explained. After receiving approval, potential exercisers and athletes were approached before their training session and asked to voluntarily participate in this study. Participants who accepted 
to partake signed an informed consent form before completing the online questionnaire. For inclusion, potential participants had to be aged above or18 years old, have more than 6 months of sport or exercise experience, and participate voluntarily in this study. The 6-months criteria was based on the Transtheoretical Model proposed by Prochaska and DiClemente (1982), specifically the maintenance phase, in which individuals with more than 6 months of regular practice are more likely to persist in physical activity. Data from three samples of athletes and exercisers were collected, 6 months apart in between samples.

\subsection{Measures}

The 24-item BRSQ Portuguese version (Monteiro et al. 2018a, b; Monteiro et al. 2019) was used to measure six behavioral regulations (four items per factor), namely: amotivation (item 1: "I play sports but I wonder what is the point"), external (item 8: "I practice sports because I feel pressure from other people to play"), introjected (item 15: "I play sports because I feel obligated to continue"), identified (item 22: "I play sports because I value the benefits"), and integrated (item 5: "I play sports because it is a part of who I am") regulation, and intrinsic motivation (item 12: "I practice sports because I enjoy doing something to the best of my ability"). Participants responded to each item on a seven-point scale ranging from 1 ("completely disagree") to 7 ("completely agree”).

The 18-item BREQ-3 Portuguese version (Cid et al. 2018) was considered. However, the six items eliminated (one per factor) in the validated Portuguese version were retreived so that participants could respond to a parsimony 24-item measurement, as proposed by the original authors of the BREQ-3 (Wilson et al. 2007). Specifically: amotivation (item 1: "I do not see exercise as important to me"); external (item 2: "I exercise because my peers say I should"); introjected (item 9: "I feel guilty when I skip an exercise session"), identified (item 22: "I value exercising because the benefits of exercise are important to me"), integrated (item 11: "I consider exercising to be an opportunity to just be who I am"), intrinsic motivation (item 6: "I exercise because I enjoy the feeling of achievement") were considered as new items. Participants responded to each stem based on a five-point scale anchored from 0 ("completely disagree") to 4 ("completely agree").

\subsection{Statistical analysis}

Data was screened for univariate and multivariate outliers and these were excluded from further analysis. No missing responses were presented given the way the online survey was set-up. Descriptive statistics (i.e., mean, standard deviation, skewness, and kurtosis) and bivariate correlations were calculated for each group of participants.

\subsubsection{Construct analysis}

All analyses were performed using Mplus 7.4 (Muthén and Muthén 2010) and estimates calculated using the Robust Maximum Likelihood (MLR) estimator since it provides standard errors and tests of model fit that are robust considering the non-normality of the data. In the first stage of the analyses, measurement models were examined based on empirical (Ryan and Deci 2017) and theoretical (Howard et al. 2016; Jowett et al. 2017) literature: a six-correlated factors CFA and six-correlated factors ESEM. Each model was tested in the exerciser sample, athlete sample, and total sample. In the CFA model specifications, items were only allowed to estimate a priori factors, factors were allowed to correlate, and 
no cross-loadings were estimated. In the ESEM models, the factors were defined as in the CFA models, however, cross-loadings were freely estimated but forced to a target value of zero using target oblique rotation procedure (Browne 2001).

Since the Chi square $(\chi 2)$ test of exact fit and respective degrees of freedom ( $\mathrm{df})$ is oversensitive to sample size and model complexity, mode fit was examined based on the following absolute and incremental indexes: Comparative Fit Index (CFI); Tucker-Lewis Index (TLI); Standardized Root Mean Square Residual (SRMR); Root Mean Square Error of Approximation (RMSEA). According to several authors (Byrne 2011; Hair et al. 2019; Marsh et al. 2019), values greater than .90 for CFI and TLI are considered to indicate acceptable fit, and values smaller than .80 for SRMR and RMSEA support adequate model fit.

\subsubsection{Multigroup analysis}

Model selection for multigroup analysis between context will be assessed according to the Satorra-Bentler Scaled Chi square difference test (Satorra and Bentler 2010). Significant differences between constrained (CFA) and freely (ESEM) estimated model will be considered, indicating a preference on the freely estimated model for measurement invariance analysis. To test measurement invariance between contexts, several levels of measurement invariance were measured according to Morin et al. (2015). The process of analyzing measurement invariance is essentially the testing of a series of increasingly restrictive hypotheses, namely: configural invariance (i.e., factor structure is the same between groups; same items associated with the same factors); weak factorial invariance (i.e., factor structure and factor loadings are equal between groups); strong invariance (i.e., item factor structure, factor loadings, and item thresholds are equal between groups), and; strict factorial invariance (i.e., item factor structure, factor loadings, item thresholds, and item residuals are equal between groups). Nested models were compared considering differences $(\Delta)$ in absolute and incremental indexes, considering $\triangle \mathrm{CFI}$ and $\triangle \mathrm{TLI}$ below .01, and $\triangle \mathrm{SRMR}$ and $\triangle$ RMSEA below.015 indicative of invariance across groups (Chen 2007; Cheung and Rensvold 2002; Marsh et al. 2019). Multigroup analysis was performed within samples (e.g., athlete samples) and between samples (i.e. athletes and exercisers).

\section{Results}

Identified and integrated regulation, as well as intrinsic motivation displayed the highest means in both contexts compared to non-self-determined regulations. All constructs presented normal distribution since skewness and kurtosis were contained within cutoffs. Correlations among behavioral regulations are in accordance with the theoretical framework. Interestingly, introjected regulation was negatively and significantly correlated with selfdetermined regulations in athletes, whereas positively correlated with identified and integrated regulations in exercisers. For more information see Table 1.

\subsection{Construct analysis}

The six-correlated factor CFA and ESEM model approach presented acceptable fit to the data in all samples, as seen in Table 2. Looking at the CFA specifications, all items in both scales presented factor loadings above .50, explaining $25 \%$ of the latent construct. 
Table 1 Descriptive statistics and correlation matrix

\begin{tabular}{|c|c|c|c|c|c|c|c|c|c|c|}
\hline & M & SD & $\mathrm{S}$ & K & 1 & 2 & 3 & 4 & 5 & 6 \\
\hline \multicolumn{11}{|l|}{ Athletes } \\
\hline 1. Amotivation & 3.18 & 1.71 & .27 & -.99 & 1 & & & & & \\
\hline 2. External & 2.22 & 1.47 & 1.40 & 1.52 & $.64 * *$ & 1 & & & & \\
\hline 3. Introjected & 2.63 & 1.62 & .84 & -.19 & $.50 * *$ & $.70^{* *}$ & 1 & & & \\
\hline 4. Identified & 5.48 & 1.02 & -.40 & .11 & $-.34 * *$ & $-.22 * *$ & $-.12 * *$ & 1 & & \\
\hline 5. Integrated & 5.65 & 1.05 & -.39 & -.32 & $-.40 * *$ & $-.32 * *$ & $-.17 * *$ & $.52 * *$ & 1 & \\
\hline 6. Intrinsic & 5.72 & 1.22 & -.81 & .16 & $-.31 * *$ & $-.34 * *$ & $-.58 * *$ & $.29 * *$ & $.49 * *$ & 1 \\
\hline \multicolumn{11}{|l|}{ Exercisers } \\
\hline 1. Amotivation & .34 & .61 & 1.94 & 6.41 & 1 & & & & & \\
\hline 2. External & .93 & .87 & .69 & .02 & $.41 * *$ & 1 & & & & \\
\hline 3. Introjected & 2.01 & .97 & -.04 & -.27 & .07 & $.28 * *$ & 1 & & & \\
\hline 4. Identified & 3.38 & .63 & -.072 & .81 & $-.31 * *$ & $-.10^{*}$ & $.38 * *$ & 1 & & \\
\hline 5. Integrated & 3.28 & .69 & -.76 & .82 & $-.31 * *$ & $-.24 * *$ & $.21 * *$ & $.48 * *$ & 1 & \\
\hline 6. Intrinsic & 3.50 & .65 & -1.36 & 2.68 & $-.41 * *$ & $-.24 * *$ & .06 & $.46^{* *}$ & $.63 * *$ & 1 \\
\hline
\end{tabular}

$\mathrm{M}=$ Mean; $\mathrm{SD}=$ Standard Deviation; $\mathrm{S}=$ Skewness $; \mathrm{K}=$ Kurtosis; $* p<.05 ; * * p<.01$

Additionally, coefficients were above cutoffs, ranging from .74 (identified regulation) to .92 (external regulation) in athletes, and from .70 (identified regulation) to .89 (amotivation) in exercisers.

Concerning factor loadings of the six-correlated factor ESEM models, items loaded significantly their respective factor as theoretically proposed. Within the athlete's sample, Item 4 presented factor loading below the .50 criteria. In the exerciser sample, Item 5 , 14, 21, and 24 also showed factor loadings below cutoffs. However, their removal did not increase model fit, thus these were removed forfurther analyses.

Some cross-loadings were observed (e.g., Item 11 in the athletes, and Item 14 in exercisers); however, their removal did not significantly increase the model fit and therefore these were maintained so that the measurement model would be as parsimonious as the original 24-item model. Composite reliability coefficients were above acceptable or close to the .70 cutoff, specifically introjected, identified and integrated regulation in the athlete's sample (Table 3). Looking at the exerciser's sample, all factors presented composite reliability coefficients above cutoffs. For more detail see Table 4.

\subsection{Multigroup analysis}

The Satorra-Bentler Scaled Chi square difference test between the six-correlated CFA and ESEM model presented no significant $(p<.001)$ differences, hence, the ESEM model was used to test measurement invariance between groups. Firstly, the model was tested within all three samples of athletes and exercisers, to examine if the model would pertain equivalence. The configural model fit the data well within samples (see Table 5). Secondly, the weak invariance model with the addition of identical factor loadings across samples provided adequate fit to the data. Thirdly, item intercepts were constrained across samples and the model provided acceptable weak factor invariance. Lastly, the strict invariance criteria were respected, since item factor structure, factor loadings, item thresholds, and item residuals were equal across samples. 
Table 2 Model fit statistics for the estimated models of the BRSQ and BREQ

\begin{tabular}{|c|c|c|c|c|c|c|}
\hline & $\chi^{2}$ & df & CFI & TLI & SRMR & RMSEA \\
\hline \multicolumn{7}{|l|}{ Athletes (BRSQ) } \\
\hline 1. One factor CFA & $3411.085^{*}$ & 252 & .448 & .440 & .147 & .150 \\
\hline 2. Two-correlated factors CFA & $2495.644 *$ & 251 & 637 & 600 & .106 & .131 \\
\hline 3. Two-correlated factors ESEM & $2632.605^{*}$ & 229 & .611 & .531 & .092 & .142 \\
\hline 14. Six-correlated factor CFA & $1058.946 *$ & 237 & .907 & .895 & .063 & .081 \\
\hline 25. Six-correlated factor ESEM & $614.858 *$ & 147 & .924 & .858 & .025 & .078 \\
\hline 6. Bifactor CFA (two S; one G) & $1340.749 *$ & 227 & .820 & .781 & .058 & .097 \\
\hline 7. Bifactor ESEM (two S; one G) & $1120.286^{*}$ & 207 & .836 & .781 & .046 & .097 \\
\hline 8. Bifactor CFA (six S; one G) & $1058.946^{*}$ & 237 & .867 & .845 & .063 & .081 \\
\hline 9. Bifactor ESEM (six S; one G) & $614.858^{*}$ & 147 & .924 & .858 & .025 & .078 \\
\hline 10. Bifactor CFA (six S; two G) & $974.988^{*}$ & 212 & .876 & .839 & .049 & .083 \\
\hline 11. Bifactor ESEM (six S; two G) & $450.578^{*}$ & 129 & .941 & .875 & .020 & .073 \\
\hline \multicolumn{7}{|l|}{ Exercisers (BREQ) } \\
\hline 12. One factor CFA & $2452.741^{*}$ & 252 & .487 & .438 & .135 & .124 \\
\hline 13. Two-correlated factors CFA & $1660.007 *$ & 251 & .671 & 638 & .117 & .099 \\
\hline 14. Two-correlated factors ESEM & $1420.637 *$ & 229 & .722 & .665 & .075 & .095 \\
\hline 315. Six-correlated factor CFA & $896.587^{*}$ & 237 & .916 & .901 & .082 & .070 \\
\hline 416. Six-correlated factor ESEM & $337.478^{*}$ & 147 & .956 & .917 & .021 & .048 \\
\hline 17. Bifactor CFA (two S; one G) & $1019.134 *$ & 227 & .822 & .801 & .053 & .054 \\
\hline 18. Bifactor ESEM (two S; one G) & $816.817 *$ & 207 & .858 & .810 & .045 & .072 \\
\hline 19. Bifactor CFA (six S; one G) & $896.587 *$ & 237 & .846 & .821 & .081 & .070 \\
\hline 20. Bifactor ESEM (six S; one G) & $337.478 *$ & 147 & .956 & .917 & .021 & .048 \\
\hline 21. Bifactor CFA (six S; two G) & $545.745^{*}$ & 212 & .884 & .823 & .054 & .079 \\
\hline 22. Bifactor ESEM (six S; two G) & $255.650^{*}$ & 129 & .970 & .937 & .016 & .041 \\
\hline \multicolumn{7}{|l|}{ Total Sample } \\
\hline 23. One factor CFA & $8647.436^{*}$ & 252 & .489 & .440 & .216 & .174 \\
\hline 24. Two-correlated factors CFA & $3964.284 *$ & 251 & .774 & .751 & .104 & .116 \\
\hline 25. Two-correlated factors ESEM & $3409.336^{*}$ & 229 & .806 & .766 & .064 & .113 \\
\hline 526. Six-correlated factor CFA & $1244.089 *$ & 237 & .939 & .929 & .047 & .062 \\
\hline 627. Six-correlated factor ESEM & $692.447 *$ & 147 & .967 & .938 & .013 & .058 \\
\hline 28. Bifactor CFA (two S; one G) & $1925.622 *$ & 227 & .896 & .874 & .046 & .083 \\
\hline 29. Bifactor ESEM (two S; one G) & $1717.598^{*}$ & 207 & .908 & .877 & .029 & .082 \\
\hline 30. Bifactor CFA (six S; one G) & $1025.412 *$ & 213 & .951 & .936 & .028 & .059 \\
\hline 31. Bifactor ESEM (six S; one G) & $691.340 *$ & 147 & .967 & .938 & .013 & .058 \\
\hline 32. Bifactor CFA (six S; two G) & $962.550 *$ & 212 & .954 & .941 & .041 & .057 \\
\hline 33. Bifactor ESEM (six S; two G) & $561.667 *$ & 129 & .974 & .944 & .011 & .055 \\
\hline
\end{tabular}

$* p<.001$

When testing the measurement model between athletes and exercisers' samples, the configural model displayed acceptable fit. However, testing for weak invariance, differences in CFI and TLI, as well as in SRMR and RMSEA were above cutoffs, rejecting assumptions of invariance. Thus, multigroup analysis between contexts stopped at this stage, since further analysis would continue to display lack of invariance. 
Table 3 Factor loadings, uniqueness and composite reliability of the six-correlated models in athletes

\begin{tabular}{|c|c|c|c|c|c|c|c|c|c|}
\hline & \multicolumn{2}{|l|}{ CFA } & \multicolumn{7}{|l|}{ ESEM } \\
\hline & $\mathrm{SF} \lambda$ & $\delta$ & $\mathrm{AMO} \lambda$ & EXT $\lambda$ & INT $\lambda$ & IDE $\lambda$ & ITE $\lambda$ & $\mathrm{IMI} \lambda$ & $\delta$ \\
\hline Amotivation & .91 & & .89 & & & & & & \\
\hline Item 1 & $.86 * *$ & .26 & $.87 * *$ & .01 & -.01 & $.09 *$ & $-.15 * *$ & .03 & .22 \\
\hline Item 7 & $.85 * *$ & .27 & $.92 * *$ & -.07 & .05 & .09 & -.02 & .01 & .24 \\
\hline Item 13 & $.84 * *$ & .30 & $.69 * *$ & .07 & .07 & $-.16^{*}$ & -.05 & .04 & .30 \\
\hline Item 19 & $.84 * *$ & .28 & $.79 * *$ & $.14^{*}$ & -.05 & $-.12 *$ & $.22 * *$ & -.02 & .22 \\
\hline External & .92 & & & .82 & & & & & \\
\hline Item 2 & $.89 * *$ & .21 & .02 & $.87 * *$ & .14 & $.19 * *$ & $-.21 * *$ & .04 & .15 \\
\hline Item 8 & $.79 * *$ & .37 & $.21 * *$ & $.56 * *$ & $.22 * *$ & .04 & -.10 & .09 & .38 \\
\hline Item 14 & $.91 * *$ & .17 & .05 & $.83 * *$ & .14 & -.04 & -.12 & .11 & .15 \\
\hline Item 20 & $.87 * *$ & .24 & $.15^{* *}$ & $.64 * *$ & $.19 * *$ & $-.20 * *$ & $.19 * *$ & .03 & .18 \\
\hline Introjected & .91 & & & & .69 & & & & \\
\hline Item 3 & $.82 * *$ & .32 & $.28 * *$ & .08 & $.55 * *$ & .04 & -.03 & $-.21 *$ & .27 \\
\hline Item 9 & $.86 * *$ & .26 & -.09 & $26 * *$ & $.66 * *$ & -.02 & .07 & -.19 & .24 \\
\hline Item 15 & $.83 * *$ & .32 & .02 & $.32 * *$ & $.50 * *$ & -.07 & .12 & $-.22 * *$ & .32 \\
\hline Item 21 & $.86 * *$ & .26 & .05 & .16 & $.68 * *$ & -.04 & .18 & -.15 & .23 \\
\hline Identified & .74 & & & & & .69 & & & \\
\hline Item 4 & $.50 * *$ & .78 & .01 & -.02 & .08 & $.48 * *$ & .08 & -.02 & .82 \\
\hline Item 10 & $.70 * *$ & .51 & $-.20 * *$ & .03 & .04 & $.55 * *$ & .05 & .05 & .54 \\
\hline Item 16 & $.58 * *$ & .66 & .03 & .04 & .01 & $.62 * *$ & .01 & .01 & .63 \\
\hline Item 22 & $.78 * *$ & .39 & .02 & .05 & $-.15^{*}$ & $.73 * *$ & $.27 * *$ & -.07 & .31 \\
\hline Integrated & .82 & & & & & & .68 & & \\
\hline Item 5 & $.62 * *$ & .62 & .03 & $-.24 * *$ & $.26^{*}$ & .17 & $.56 * *$ & .11 & .63 \\
\hline Item 11 & $.79 * *$ & .38 & $-.15^{* *}$ & $-.36 * *$ & $.15^{*}$ & .08 & $.53 *$ & $.45^{* *}$ & .35 \\
\hline Item 17 & $.71 * *$ & .50 & -.07 & -.08 & .10 & .18 & $.58 * *$ & $.20 * *$ & .55 \\
\hline Item 23 & $.77 * *$ & .41 & -.06 & -.03 & -.01 & $.31 * *$ & $.68 * *$ & .08 & .28 \\
\hline Intrinsic & .90 & & & & & & & .83 & \\
\hline Item 6 & $.87 * *$ & .25 & -.03 & .04 & $-.12 *$ & -.03 & .05 & $.80 * *$ & .27 \\
\hline Item 12 & $.87 * *$ & .24 & $.09 *$ & .00 & -.13 & .05 & -.15 & $.93 * *$ & .11 \\
\hline Item 18 & $.77 * *$ & .41 & $-.09^{*}$ & $.22 * *$ & -.14 & -.05 & $.25^{* *}$ & $.70 * *$ & .35 \\
\hline Item 24 & $.81 * *$ & .35 & -.03 & .02 & $-.24 *$ & .07 & $.35^{* *}$ & $.53 * *$ & .28 \\
\hline
\end{tabular}

$\mathrm{SF}=$ Specific Factor; $\mathrm{GF}=$ Global Factor; $\mathrm{AMO}=$ Amotivation; $\mathrm{EXT}=$ External; $\mathrm{INT}=\mathrm{Introjected}$; $\mathrm{IDE}=$ Identified; ITE = Integrated; IMI = Intrinsic; $\lambda=$ standardized factor loadings; $\delta=$ uniqueness; target loadings are in bold; composite reliability coefficients in italic; $* p<.05 ; * * p<.001$

\section{Discussion}

This study aimed to test whether the BRSQ and BREQ-3 can measure the same constructs in an equivalent manner. First, the BREQ-3 Portuguese version was revised, examining the factor structure of a parsimony 24-item measurement scale. Afterwards, multigroup analysis was performed between contexts, specifically, between sport and exercise. The BRSQ and BREQ-3 attempt to capture the motivations underlying the behavior in the sport and exercise context, thereby assessing how individuals engage in physical activity dependent 
Table 4 Factor loadings, uniqueness and composite reliability of the six-correlated models in exercisers

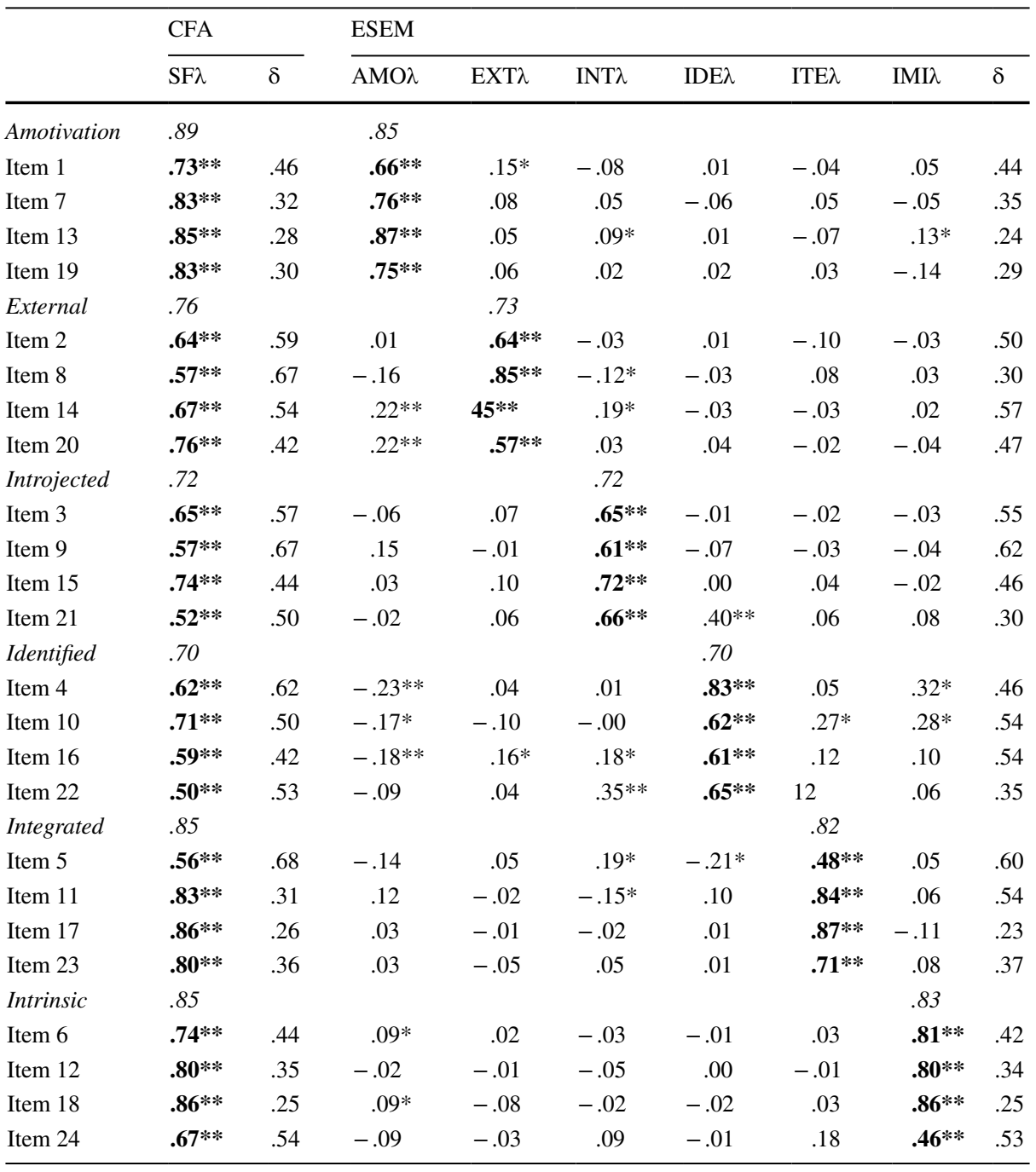

$\mathrm{SF}=$ Specific Factor; $\mathrm{GF}=$ Global Factor; $\mathrm{AMO}=$ Amotivation; $\mathrm{EXT}=$ External; $\mathrm{INT}=\mathrm{Introjected}$; IDE = Identified; ITE = Integrated; IMI = Intrinsic; $\lambda=$ standardized factor loadings; $\delta=$ uniqueness; target loadings are in bold; composite reliability coefficients in italic; $* p<.05 ; * * p<.001$

on self-determined behavior (Deci et al. 2017). However, there seems to be a distinctive difference between how motivation is conceptualized and measured in each context.

To compare measures between sport and exercise context, both scales were initially analyzed for dimensionality and validity, testing CFA and ESEM model specifications. The examination on the 24-item BRSQ and BREQ-3 scale on both samples extracted sixcorrelated dimensions, assessing all six types of behavior regulations based on the SDT framework (Ryan and Deci 2017). These results support the original BRSQ (Lonsdale et al. 2008) and BREQ-3 (Rodgers et al. 2010) as well as empirical studies using these 
Table 5 Multigroup Analysis using the six-correlated ESEM model specification

\begin{tabular}{lcccccccccc}
\hline \multicolumn{1}{c}{$\chi^{2}$} & $\mathrm{df}$ & $\mathrm{CFI}$ & $\Delta \mathrm{CFI}$ & TLI & $\Delta$ TLI & SRMR & $\Delta$ SRMR & RMSEA & $\Delta$ RMSEA \\
\hline Within athlete samples & & & & & & & & & \\
Configural & $927.276^{*}$ & 318 & .959 & - & .959 & - & .026 & - & .055 & - \\
Weak & $964.712^{*}$ & 426 & .964 & .005 & .953 & .006 & .030 & .004 & .045 & .010 \\
Strong & $969.421^{*}$ & 428 & .966 & .007 & .956 & .003 & .030 & .000 & .046 & .009 \\
Strict & $971.121^{*}$ & 444 & .964 & .005 & .956 & .003 & .030 & .000 & .044 & .011 \\
Within exerciser samples & & & & & & & & & \\
Configural & $1320.148^{*}$ & 318 & .927 & - & .910 & - & .049 & - & .050 & - \\
Weak & $1424.136^{*}$ & 426 & .921 & .006 & .907 & .003 & .055 & .006 & .055 & .005 \\
Strong & $1494.367^{*}$ & 428 & .920 & .007 & .903 & .007 & .060 & .011 & .056 & .006 \\
Strict & $1543.765^{*}$ & 444 & .920 & .007 & .900 & .010 & .060 & .011 & .059 & .009 \\
Between athletes and exercisers & & & & & & & & \\
Configural & $1004.182^{*}$ & 318 & .955 & - & .916 & - & .023 & - & .066 & - \\
Weak & $1831.593^{*}$ & 426 & .910 & .045 & .876 & .040 & .064 & .039 & .081 & .015 \\
\hline
\end{tabular}

$\Delta=$ differences; $* p<.001$

instruments (Cece et al. 2019; Monteiro et al. 2018a, b; Rodrigues et al. 2019; Teixeira et al. 2019). Additionally, current results confirmed that all dimensions were internally consistent, as values of composite reliability were above or very close to cutoffs (Hair et al. 2019; Nunally 1978).

Some cross-loadings presented differences below .15 showing no significant item overlap on two or more latent factors, hence accepting the factor in which the item loaded more significantly (Hair et al. 2019). In other cases, cross-loadings were significant in two factors (e.g., Item 11 loaded identified and integrated regulation in the athlete sample), thus items were removed from the original targeted factor. The significant loading in two factors could be explained by the internalization of the behavior. Since behavioral regulations are spread along a motivational continuum, items could share conceptual definitions in one factor (i.e., behavioral regulation) and its nearest one. For example, Item 11 (stem "I play sports because it is a part of me") could be perceived by some athletes as a more integrative behavior, whereas others could engage in sports practice because they consciously value the behavior and accept it as personally important. Overall, the results from our factor and construct analysis are in agreement with the theoretical framework proposed by SDT (Ryan and Deci 2017) and the empirical studies examining the factor structure of the BRSQ and BREQ-3.

As it was speculated, even though the BRSQ and BREQ-3 measure the same constructs, the measurement model did not achieve measurement invariance. These results support the need to use validated scales as stated by several authors (Chen 2008; Ryan 1995), avoiding important methodological limitations associated with non-adaptation of questionnaires to the context under analysis. Thus, research conducted in the past using non-validated scales could display bias results (Gaston et al. 2016; Román et al. 2019).

Athletes' perception of coaches' interpersonal behaviors (Rocchi and Pelletier 2018), and exercisers' perception of fitness instructors' supportive behaviors (Klain, et al. 2015; Ntoumanis et al. 2017) could influence how individuals regulate their behavior towards physical activity. Thus, these individuals in key positions can engage in differentiated behaviors. For example, coaches, in addition to teaching sport-specific skills, 
should communicate with athletes to push themselves in order to achieve higher performance in competitions, since winning is an expected outcome for both parties (Bloom et al. 2014). In gym and health clubs, fitness professionals are attentive on promoting regular exercise participation, hence their communication style is associated with gym members behavior persistence (Ntoumanis et al. 2017) and not specifically with performance and rewards.

To the best of our knowledge, no study until now has compared athletes' and exercisers' motivational patterns. Therefore, the results from the present study contribute to extend current knowledge by filling up an existing gap in the literature. Even though findings display non-invariance between groups, a possible interpretation for the differences among the BRSQ (i.e., athletes) and BREQ-3 (i.e., exercisers) could be associated with the particularities of each environment (Howley 2001), which may reflect differences in athletes' and exercisers' perceptions of each behavioral regulation. For example, in sport context, athletes are conditioned to schedules, and have a competitive component associated to physical exercise, in which winning is a fundamental element, pushing sometimes athletes to extreme behaviors. On the other hand, exercisers participate in regular physical activity without constraints and whenever they choose to plan their sessions, thus, there is virtually no competitiveness between members. Specifically, managers and fitness professionals generally do not compare and award gym members with better body composition (e.g., higher muscle mass percentage) or improved behavior (e.g., higher gym frequency).

\subsection{Limitations and agenda for future research}

Although the findings from this study provide initial evidence of the distinctiveness of measures in the sport and the exercise domains, the results should be considered in light of possible limitations. First, differences between scales could be related to the number of scale points. The BRSQ uses a 7-point scale (from 1 to 7) whereas the BREQ-3 uses a 5 point (from 0 to 4). Literature indicates that an increase in the number of scale points could lead to greater differentiation between items in a questionnaire, thus higher scale points indicate higher variability (Clancy et al. 2017). Therefore, a possible explanation to current results could be attributed to athletes' ability to better discriminate items on a 7-point scale rather than exercisers on a 5-point scale. Forthcoming studies are suggested to test for a 7-point scale on the BREQ-3 measure and examine its psychometric proprieties.

Second, future studies should provide both instruments to the same group of people. For example, ask individuals to respond to both measures preceded by context general stems ("I participate in my sport..." and "I Exercise..."). Nevertheless, some items of both scales were similar or even equal. For example, one item measuring intrinsic motivation was equal in both scales "...because it is fun". Another item, measuring identified regulation "I value the benefits of my..." was also equal in both scales. One item assessing external regulation shared similar sentence syntax: “... other people will not be pleased with me". Hence, we feel that the representativeness of items/stems in each instrument could be an important aspect of examination in future studies when comparing both scales.

Lastly, some demographic characteristics such as age and physical activity experience may have influenced current results. This limitation is constrained by the context itself, since some are exercising at the gym and others are athletes. Athletes are limited to a certain competitive level (for example soccer: Under-8; Under-10; Under-12; Under-14; Under-16; Under-18 and over 18 years old). In the exercise context, there are no levels 
of progress or age limits. Thus, training experience and frequency are determined by the context.

\section{Conclusion}

The Portuguese version of the BRSQ and BREQ-3 seem to be reliable and validated measures of motivation, conceptualizing all behavioral regulations proposed by SDT. Invariance was not achieved between contexts, highlighting the need to use context specific scales to unfailingly measure how individuals regulate their behaviors in a given context.

Research should be bound to the specificity of the context and scales validated in one context should not be used in another prior to validation. We hope this examination of context invariance analysis using validated scales can further help advance conceptual understanding of the measurement in sport and exercise. Scale assessment is a complex and constant process and should not be viewed as a strict and definite approach. This study opens doors to future instrument examination using more advanced statistical methodologies and showing their strengths and weaknesses when defining motivation.

Funding This work was supported by the National Funding through the Portuguese Foundation for Science and Technology, I.P., under the Project UID/DTP/04045/2019 for the authors Luís Cid and Diogo Monteiro; and under the Project UIDP/04748/2020 for the author Filipe Rodrigues.

\section{Compliance with ethical standards}

Conflict of interest The authors declare no conflict of interest.

Ethical approval Approval from the Ethical Committee of Beira Interior University (CE-UBI-pJ2018-044:ID683) was obtained.

\section{References}

Bartholomew, K., Ntoumanis, N., Ryan, R., Thogersen-Ntoumani, C.: Psychological need thwarting in the sport context: assessing the darker side of athletic experience. J. Sport Exerc. Psychol. 1, 75-102 (2011). https://doi.org/10.1123/jsep.33.1.75

Bloom, G., Falcão, W., Caron, J.: Coaching high performance athletes: implications for coach training. In: Gomes, A., Resende, R., Albuquerque, A. (eds.) Positive Human Functioning from a Multidimensional Perspective. Nova Science, Hauppauge (2014)

Browne, M.W.: An overview of analytic rotation in exploratory factor analysis. Multivariate Behav. Res. 36(1), 111-150 (2001). https://doi.org/10.1207/S15327906MBR3601_05

Byrne, B.: Structural Equation Modeling with Mplus-Basic Concepts, Applications, and Programming. Routledge, Abingdon (2011)

Cece, V., Lienhart, N., Nicaise, V., Guillet-Descas, E., Martinent, G.: Longitudinal sport motivation among young athletes in intensive training settings: using methodological advances to explore temporal structure of youth behavioral regulation in sport questionnaire scores. J. Sport Exerc. Psychol. 41(1), 24-35 (2019). https://doi.org/10.1123/jsep.2017-0194

Chen, F.: Sensitivity of goodness of fit indexes to lack of measurement invariance. Struct. Equ. Model. A Multidiscip. J. 14(3), 464-504 (2007). https://doi.org/10.1080/10705510701301834

Chen, F.: What happens if we compare chopsticks with forks? The impact of making inappropriate comparisons in cross-cultural research. J. Person. Soc. Psychol. 95(5), 1005-1018 (2008). https://doi. org/10.1037/a0013193 
Cheung, G., Rensvold, R.: Evaluating Goodness-of-Fit Indexes for testing measurement invariance. Struct. Equ. Model. A Multidiscip. J. 9(2), 233-255 (2002). https://doi.org/10.1207/s15328007sem0902_5

Cid, L., Monteiro, D., Teixeira, D., Teques, P., Alves, S., Moutao, J., Palmeira, A.: The behavioral regulation in exercise questionnaire (BREQ-3) Portuguese-version: evidence of reliability, validity and invariance across gender. Front Psychol. 9, 1940 (2018). https://doi.org/10.3389/fpsyg.2018.01940

Clancy, R., Herring, M., Campbell, M.: Motivation measures in sport: a critical review and bibliometric analysis. Front Psychol. 8, 348 (2017). https://doi.org/10.3389/fpsyg.2017.00348

Costa, R., Probst, M., Bastos, T., Vilhena, E., Seabra, A., Corredeira, R.: Behavioural regulation in exercise questionnaire in people with schizophrenia: construct validity of the Portuguese versions. Disabil. Rehabil. 40(21), 2577-2584 (2018). https://doi.org/10.1080/09638288.2017.1342277

Deci, E., Olafsen, A., Ryan, R.: Self-determination theory in work organizations: the state of a science. Ann. Rev. 4, 19-43 (2017). https://doi.org/10.1146/annurev-orgpsych032516-113108

Deci, E., Ryan, R.: Intrinsic Motivation and Self-Determination in Human Behavior. Plenum Press, New York (1985)

Deci, E., Ryan, R.: Self-determination theory: a macrotheory of human motivation, development, and health. Canad. Psychol. 49(3), 182-185 (2008). https://doi.org/10.1037/a0012801

Gardner, L., Magee, C., Vella, S.: Enjoyment and behavioral intention predict organized youth sport participation and dropout. J. Phys. Act. Health 14(11), 861-865 (2017). https://doi.org/10.1123/ jpah.2016-0572

Gaston, A., De Jesus, S., Markland, D., Prapavessis, H.: I sit because I have fun when I do so! Using selfdetermination theory to understand sedentary behavior motivation among university students and staff. Health Psychol. Behav. Med. 4(1), 138-154 (2016). https://doi.org/10.1080/21642850.2016.1170605

Hagger, M., Chatzisarantis, N.: Integrating the theory of planned behaviour and self-determination theory in health behaviour: a meta-analysis. Br. J. Health. Psychol. 14(2), 275-302 (2009). https://doi. org/10.1348/135910708X373959

Hagger, M., Hardcastle, S., Chater, A., Mallett, C., Pal, S., Chatzisarantis, N.: Autonomous and controlled motivational regulations for multiple health-related behaviors: between- and within-participants analyses. Health Psychol. Behav. Med. 2(1), 565-601 (2014). https://doi.org/10.1080/21642850.2014.91294 5

Hair, J., Black, W., Babin, B., Anderson, R.: Multivariate Data Analysis, 8th edn. Pearson Educational In, New Jersey (2019)

Howard, J., Gagne, M., Morin, A., Wang, Z., Forest, J.: Using bifactor exploratory structural equation modeling to test for a continuum structure of motivation. J. Manag. (2016). https://doi.org/10.1177/01492 06316645653

Howley, E.: Type of activity: resistance, aerobic and leisure versus occupational physical activity. Med. Sci. Sports Exerc. 33(6), 364-369 (2001)

Jowett, S., Adie, J., Bartholomew, K., Yang, S., Gustafsson, H., Lopez-Jiménez, A.: Motivational processes in the coach-athlete relationship: A multi-cultural self-determination approach. Psychol. Sport Exerc. 32, 143-152 (2017). https://doi.org/10.1016/j.psychsport.2017.06.004

Klain, I., de Matos, D., Leitao, J., Cid, L., Moutao, J.: Self-determination and physical exercise adherence in the contexts of fitness academies and personal training. J. Hum. Kinet. 46, 241-249 (2015). https://doi. org/10.1515/hukin-2015-0052

Lonsdale, C., Hodge, K., Rose, E.A.: The behavioral regulation in sport questionnaire (BRSQ): instrument development and initial validity evidence. J. Sport Exerc. Psychol. 30(3), 323 (2008). https://doi. org/10.1123/jsep.30.3.323

Lonsdale, C., Hodge, K., Hargreaves, E.A., Ng, J.Y.Y.: Comparing sport motivation scales: a response to Pelletier, et al. Psychol. Sport Exerc. 15(5), 446-452 (2014). https://doi.org/10.1016/j.psychsport .2014 .03 .006

Mallett, C., Kawabata, M., Newcombe, P., Otero-Forero, A., Jackson, S.: Sport motivation scale-6 (SMS6): a revised six-factor sport motivationscale. Psychol. Sport Exerc. 8(5), 600-614 (2007). https://doi. org/10.1016/j.psychsport.2006.12.005

Markland, D., Tobin, V.: A modification to the behavioural regulation in exercise questionnaire to include an assessment of amotivation. J. Sport Exerc. Psychol. 26(2), 191-196 (2004). https://doi.org/10.1123/ jsep.26.2.191

Marsh, H., Guo, J., Dicke, T., Parker, P., Craven, R.: Confirmatory factor analysis (CFA), exploratory structural equation modeling (ESEM), and set-ESEM: optimal balance between goodness of fit and parsimony. Multivariate Behav. Res. (2019). https://doi.org/10.1080/00273171.2019.1602503

Monteiro, D., Borrego, C., Silva, C., Moutao, J., Marinho, D., Cid, L.: Motivational climate sport youth scale: measurement invariance across gender and five different sports. J. Hum. Kinet. 61, 249-261 (2018a). https://doi.org/10.1515/hukin-2017-0124 
Monteiro, D., Moutão, J., Cid, L.: Validation of the behavioural regulation in sport questionnaire in Portuguese athletes. J. Sport Psychol. 27(1), 0145-0150 (2018b)

Monteiro, D., Pelletier, L., Moutão, J., Cid, L.: Examining the motivational determinants of enjoyment and the intention to continue of persistent competitive swimmers. Int. J. Sport Psychol. 49(6), 484-504 (2018c). https://doi.org/10.7352/ijsp.2018.49.484

Monteiro, D., Teixeira, D., Vitorino, A., Moutao, J., Rodrigues, F., Machado, S., Cid, L.: Behavioral regulation sport questionnaire: gender and sport invariance in Portuguese Athletes. Percept. Motor Skills 126(2), 323-341 (2019). https://doi.org/10.1177/0031512519825700

Moreno-Murcia, J., Belando, N., Huéscar, E., Torres, M.: Social support, physical exercise and life satisfaction in women. Revista Latinoamericana de Psicología 49(3), 194-202 (2017). https://doi. org/10.1016/j.rlp.2016.08.002

Morin, A., Arens, A., Marsh, H.: A bifactor exploratory structural equation modeling framework for the identification of distinct sources of construct-relevant psychometric multidimensionality. Struct. Equ. Model. A Multidiscip. J. 23(1), 116-139 (2015). https://doi.org/10.1080/10705511.2014.961800

Mullan, E., Markland, D., Ingledew, D.K.: A graded conceptualisation of self-determination in the regulation of exercise behaviour: Development of a measure using confirmatory factor analytic procedures. Personal. Individ. Diff. 23(5), 745-752 (1997). https://doi.org/10.1016/S0191-8869(97)00107-4

Muthén, L., Muthén, B.: Mplus User's Guide. Muthén \& Muthén, Los Angeles (2010)

Ng, J., Ntoumanis, N., Thogersen-Ntoumani, C., Stott, K., Hindle, L.: Predicting psychological needs and well-being of individuals engaging in weight management: the role of important others. Appl. Psychol. Health Well-Being 5(3), 291-310 (2013). https://doi.org/10.1111/aphw.12011

Ntoumanis, N., Biddle, S.: A review of motivational climate in physical activity. J. Sports Sci. 17(8), 643665 (1999). https://doi.org/10.1080/026404199365678

Ntoumanis, N., Thogersen-Ntoumani, C., Quested, E., Hancox, J.: The effects of training group exercise class instructors to adopt a motivationally adaptive communication style. Scand. J. Med. Sci. Sports 27(9), 1026-1034 (2017). https://doi.org/10.1111/sms.12713

Nunally, J.: Psychometric Theory, 2nd edn. McGraw-Hill, New York (1978)

Pelletier, L.G., Rocchi, M.A., Vallerand, R.J., Deci, E.L., Ryan, R.M.: Validation of the revised sport motivation scale (SMS-II). Psychol. Sport Exerc. 14(3), 329-341 (2013). https://doi.org/10.1016/j.psych sport.2012.12.002

Pelletier, L.G., Tuson, K.M., Fortier, M.S., Vallerand, R.J., Briére, N.M., Blais, M.R.: Toward a new measure of intrinsic motivation, extrinsic motivation, and amotivation in sports: the sport motivation scale (SMS). J. Sport Exerc. Psychol. 17(1), 35-53 (1995). https://doi.org/10.1123/jsep.17.1.35

Prochaska, J., DiClemente, C.: Transtheoretical therapy: toward a more integrative model of change. Psychother. Theory Res. Practice 19(3), 276-288 (1982). https://doi.org/10.1037/h0088437

Puigarnau, S.: Self-determination in a physical exercise program to promote healthy habits in sedentary adults: a mixed methods approach. Psychol. Behav. Sci. Int. J. 7(3), 1 (2017). https://doi.org/10.19080 /pbsij.2017.07.555714

Rocchi, M., Pelletier, L.: How does coaches' reported interpersonal behavior align with athletes' perceptions? Consequences for female athletes' psychological needs in sport. Sport Exerc. Perform. Psychol. 7(2), 141-154 (2018). https://doi.org/10.1037/spy0000116

Rodgers, W., Hall, C., Duncan, L., Pearson, E., Milne, M.: Becoming a regular exerciser: examining change in behavioural regulations among exercise initiates. Psychol. Sport Exerc. 11(5), 378-386 (2010). https ://doi.org/10.1016/j.psychsport.2010.04.007

Rodrigues, F., Bento, T., Cid, L., Pereira Neiva, H., Teixeira, D., Moutao, J., Monteiro, D.: Can interpersonal behavior influence the persistence and adherence to physical exercise practice in adults? A Syst. Rev. Front Psychol. 9, 2141 (2018). https://doi.org/10.3389/fpsyg.2018.02141

Rodrigues, F., Teixeira, D., Cid, L., Monteiro, D.: Have you been exercising lately? Testing the role of past behavior on exercise adherence. J. Health Psychol. (2019). https://doi.org/10.1177/1359105319878243

Román, M., Batista, M., Lopez, J., Muñoz, S., \& Jiménez-Castuera, R. (2019). Motivación y ansiedad precompetititva en balomano - diferencias entre jugadores de categoría de alto rendimiento y de base Psicologia do Desporto e Exercício - Abordagens Pedagógicas de Investigação: Câmara Municipal de Idanha-a-Nova

Ryan, R.: Psychological needs and the facilitation of integrative processes. J. Person. 63(3), 397-427 (1995). https://doi.org/10.1111/j.1467-6494.1995.tb00501.x

Ryan, R., Bradshaw, E., Deci, E.: A history of motivation theories in psychology. In: Sternberg, R., Pickren, W. (eds.) The Cambridge Handbook fo the Intellectual History of Psychology. Cambridge University Press, Cambridge (2019)

Ryan, R., Deci, E.: Self-Determination. Theory Basic Psychological Needs in Motivation, Development, and Wellness. Guildford Press, New York (2017) 
Satorra, A., Bentler, P.: Ensuring positiveness of the scaled difference Chi square test statistic. Psychometrika 75(2), 243-248 (2010). https://doi.org/10.1007/s11336-009-9135-y

Teixeira, D.S., Pelletier, L.G., Monteiro, D., Rodrigues, F., Moutao, J., Marinho, D., Cid, L.: Motivational patterns in persistent swimmers: a serial mediation analysis. Eur. J. Sport Sci. (2019). https://doi. org/10.1080/17461391.2019.1675768

Teixeira, P., Carraca, E., Markland, D., Silva, M., Ryan, R.: Exercise, physical activity, and self-determination theory: a systematic review. Int. J. Behav. Nutr. Phys. Activ. 9, 78 (2012). https://doi. org/10.1186/1479-5868-9-78

Tornero-Quiñones, I., Sáez-Padilla, J., Viera, E., Ferrete, J.J., Robles, Á.: Risk of dependence on sport in relation to body dissatisfaction and motivation. Sustainability 11(19), 5299 (2019). https://doi. org/10.3390/su11195299

Wilson, P.M., Rodgers, W.M., Loitz, C.C., Scime, G.: "It's who i am ... really!" the importance of integrated regulation in exercise contexts. J. Appl. Biobehav. Res. 11(2), 79-104 (2007). https://doi. org/10.1111/j.1751-9861.2006.tb00021.x

Publisher's Note Springer Nature remains neutral with regard to jurisdictional claims in published maps and institutional affiliations. 